\title{
Cigarette Smoke and Inflammation: Role in Cerebral Aneurysm Formation and Rupture
}

\author{
Nohra Chalouhi, ${ }^{1}$ Muhammad S. Ali, ${ }^{1}$ Robert M. Starke, ${ }^{2}$ Pascal M. Jabbour, ${ }^{1}$ \\ Stavropoula I. Tjoumakaris, ${ }^{1}$ L. Fernando Gonzalez, ${ }^{1}$ Robert H. Rosenwasser, ${ }^{1}$ \\ Walter J. Koch, ${ }^{3}$ and Aaron S. Dumont ${ }^{1,4}$ \\ ${ }^{1}$ Joseph and Marie Field Cerebrovascular Research Laboratory, Division of Neurovascular \& Endovascular Surgery, \\ Department of Neurological Surgery, Thomas Jefferson University, Philadelphia, PA 19107, USA \\ ${ }^{2}$ Department of Neurological Surgery, University of Virginia School of Medicine, Charlottesville, VA 22903, USA \\ ${ }^{3}$ Center for Translational Medicine and George Zallie and Family Laboratory for Cardiovascular Gene Therapy, \\ Department of Medicine, Thomas Jefferson University, Philadelphia, PA 19107, USA \\ ${ }^{4}$ Division of Neurovascular \& Endovascular Surgery, Department of Neurological Surgery, Thomas Jefferson University, \\ 901 Walnut Street, 3rd Floor, Philadelphia, PA 19107, USA
}

Correspondence should be addressed to Aaron S. Dumont, aaron.dumont@jefferson.edu

Received 18 August 2012; Accepted 27 October 2012

Academic Editor: Giuseppe Valacchi

Copyright (c) 2012 Nohra Chalouhi et al. This is an open access article distributed under the Creative Commons Attribution License, which permits unrestricted use, distribution, and reproduction in any medium, provided the original work is properly cited.

Smoking is an established risk factor for subarachnoid hemorrhage yet the underlying mechanisms are largely unknown. Recent data has implicated a role of inflammation in the development of cerebral aneurysms. Inflammation accompanying cigarette smoke exposure may thus be a critical pathway underlying the development, progression, and rupture of cerebral aneurysms. Various constituents of the inflammatory response appear to be involved including adhesion molecules, cytokines, reactive oxygen species, leukocytes, matrix metalloproteinases, and vascular smooth muscle cells. Characterization of the molecular basis of the inflammatory response accompanying cigarette smoke exposure will provide a rational approach for future targeted therapy. In this paper, we review the current body of knowledge implicating cigarette smoke-induced inflammation in cerebral aneurysm formation/rupture and attempt to highlight important avenues for future investigation.

\section{Introduction}

Cigarette smoking is a major health hazard, with 5.4 million premature deaths worldwide every year and an average loss of 13 to 15 years of life expectancy [1]. Among the numerous serious health risks attributed to smoking, cerebral aneurysms stand as a major and potentially devastating clinical problem. Despite considerable advances in diagnostic methods, surgical techniques, and perioperative management, the outcome for patients with aneurysmal subarachnoid hemorrhage (SAH) remains poor, with mortality rates as high as $65 \%$ and morbidity rates in the range of $50 \%$ among survivors $[2,3]$. Cigarette smoke (CS) is the most significant modifiable risk factor for cerebral aneurysm formation. Additionally, CS is a major risk factor for rupture with a hazard ratio reportedly as high as 3-4 $[4,5]$. Up to $80 \%$ of patients who sustain an aneurysmal SAH have a history of smoking, and $50-60 \%$ are current smokers. Despite the strength of this association, the underlying pathogenic pathways remain largely unknown. A burgeoning but currently incomplete body of evidence suggests that vascular inflammation, a key component of cerebral aneurysm pathogenesis, may provide the common link between cigarette smoking and aneurysm formation and rupture. Accordingly, exposure to chemicals in cigarette smoke has consistently been shown to have a significant effect on various pathways of the immune/inflammatory response in the cerebrovascular system [6,7]. This complex interplay between CS and vascular inflammation in cerebral aneurysm pathogenesis may represent an important target for future 
therapy. The present discussion critically evaluates the existing body of literature implicating active and passive cigarette smoking in aneurysm formation/rupture and attempts to highlight important avenues for future investigation.

\section{Cigarette Smoke}

CS is a complex and reactive mixture of some 5000 chemicals generated upon burning of the ingredients of tobacco. Some smoke components such as carbon monoxide, carbon dioxide, and nitrogen dioxide are gases. Others such as nicotine, phenol, polyaromatic hydrocarbons, and certain tobaccospecific nitrosamines are contained in the particulate phase which may also enter the bloodstream. The particulate phase of CS contains $>10^{17}$ free radicals per $\mathrm{g}$, and the gas phase contains $>10^{15}$ free radicals per puff [8]. The radicals contained in the tar phase are long-lived (hours to months), whereas those associated with the gas phase have a shorter life span (seconds) [8]. Nicotine, carbon monoxide, reactive oxygen species (ROS), and acrolein are CS toxins with significant inflammatory and immunomodulatory potential [6].

Passive smoking from exposure to environmental tobacco smoke has been shown to increase the risk of cardiovascular disease including ischemic stroke $[9,10]$. Moreover, it is estimated that passive smoking is the third leading preventable cause of death in the United States, behind active smoking and alcohol [9]. Despite the proven deleterious effects of passive smoking, data implicating environmental tobacco smoke exposure in aneurysm formation and rupture are lacking. An epidemiologic study by Anderson et al. [11] that included 432 cases of SAH matched to $473 \mathrm{SAH}$-free controls did not find an association between passive smoking and SAH. However, the study was underpowered to detect small risks of SAH in subjects exposed to passive smoking. Also, measurement of exposure to environmental smoke was limited only to the home and did not include the workplace or other areas, which may have underestimated the potential association between passive smoking and SAH.

\section{Pathogenesis of Cerebral Aneurysms: An Overview}

Accrued data suggest that aneurysm formation begins with endothelial dysfunction in response to alterations in flow and shear stress (e.g., arterial bifurcations) [12-14]. The endothelial dysfunction leads to compensatory responses that alter the normal homeostatic properties of the endothelium. Subsequent functional and morphological changes in the endothelium trigger a mounting inflammatory response in the vessel wall involving leukocytes, cytokines, adhesion molecules, immunoglobulins, complement, and many other key inflammatory components $[15,16]$. An important aspect of this inflammatory reaction is the phenotypic modulation of vascular smooth muscle cells (VSMC) from a contractile and differentiated phenotype into a proinflammatory and dedifferentiated phenotype. Collectively, these changes lead to extracellular matrix remodeling by matrix metalloproteinases (MMP) with loss of the internal elastic lamina, thinning of the media, and aneurysm formation [17-19]. Continued inflammation, loss of VSMC with decreased collagen synthesis, and excessive extracellular matrix breakdown culminate in aneurysm rupture and SAH [20].

Recent reports suggest that one of the major contributing factors to cerebral aneurysm formation is the "genetic makeup" of the individual. The role of genetics is highlighted by the increased risk of cerebral aneurysms in first-degree relatives of SAH patients [4]. The prevalence of cerebral aneurysms is reportedly $2.3 \%$ in the general population, $4 \%$ in people with 1 affected first-degree relative, and $8 \%$ in those with 2 affected first-degree relatives [21]. The increased incidence with genetic diseases such as adult polycystic kidney disease, Ehler-Danlos type IV, and fibromuscular dysplasia also supports a genetic contribution to aneurysm formation and rupture [4]. Although several associations have been made between cerebral aneurysms and specific genetic polymorphisms, none of these associations have been consistently reproducible [22]. Candidate genes are those associated with vascular wall formation, response of the cerebral artery to increased stress, or those implicated in connective tissue disorders. A recent study that included 298 cases and 488 controls examined whether type III collagen variants contribute to the risk of sporadic intracranial aneurysms in the Chinese population [23]. The study found that the functional variant of COL3A1 conferred a 1.71fold increased risk for cerebral aneurysms. The elastin locus has also been found to be implicated in aneurysm genesis, though definitive evidence is still lacking [24, 25]. Yasuno et al. [26] provided evidence for a significant association between endothelin receptor type A gene and cerebral aneurysms, while Khurana et al. [27] identified a set of endothelial NO synthase (eNOS) gene polymorphisms that were more prevalent among patients with ruptured versus unruptured cerebral aneurysms. Several other candidate genes have been investigated such as transforming growth factor $\beta$ receptors, elastase, polycystin, and fibrillin, with varying results [22, 28-30]. Most of the gene variants implicated in intracranial aneurysms are CS targets, and this will be reviewed in detail in this paper. Although the exact gene variants that are associated with intracranial aneurysms have yet to be found, smoking appears to greatly enhance their effect. This has been recently demonstrated by Deka et al. [31] who found that the variants on chromosomes $8 \mathrm{q}$ and $9 \mathrm{p}$ are associated with intracranial aneurysms and that the risk of aneurysm formation in patients with these variants is greatly increased with cigarette smoking.

The risk of SAH is increased by the presence of symptomatic, large $(>7 \mathrm{~mm})$, and posterior circulation aneurysms [32]. Female sex, hypertension, excessive alcohol consumption, and cocaine abuse are important risk factors for $\mathrm{SAH}$ [33]. Vlak et al. [34] identified 8 trigger factors for aneurysmal rupture, namely, coffee consumption, cola consumption, anger, startling, straining for defecation, sexual intercourse, nose blowing, and vigorous physical exercise. A recent casecontrol study from 4 Australasian cities found that frequent intake of fat increases the risk of SAH while frequent use 
of skim or reduced-fat milk and fruit is protective against SAH [35]. Dietary antioxidants and soy products have also been found to be protective against the development of SAH in case-control studies, but prospective data are needed to confirm these findings $[36,37]$.

\section{The Role of Atherosclerosis}

The presence of atherosclerotic lesions in vessel walls is a significant feature of cerebral aneurysms [38, 39]. Small aneurysms typically demonstrate diffuse intimal thickening composed predominantly of proliferating VSMC whereas larger aneurysms have advanced atherosclerotic plaques with alternating layers of lipid-laden macrophages and mature VSMC. The observation that atherosclerotic lesions are found even in the smallest aneurysms and that progression of these lesions correlates positively with aneurysmal growth has led many investigators to hypothesize that atherosclerosis underlies cerebral aneurysm formation, growth, and rupture [38-41]. This is further corroborated by the fact that atherosclerosis is a crucial element in the causal pathway for aneurysms arising elsewhere in the body, particularly abdominal aortic aneurysms [42-44].

In a potential link to cerebral aneurysm formation, CS mediates various critical signaling pathways that underlie vascular inflammation in atherogenesis. In fact, CS results in endothelial dysfunction with impaired NO-dependant vasodilatory function and elevates various proinflammatory cytokines involved in atherosclerosis with subsequent recruitment and transendothelial migration of leukocytes [45-49]. Additionally, CS causes VSMC stimulation/proliferation and increases oxidative modification of low density lipoproteins (LDL) which are subsequently taken up by modified macrophages to form foam cells [45-49]. Most of these abnormalities are accounted for by free radicalmediated oxidative stress from CS exposure [48]. Taken together, these data indicate that the pivotal role of CSinduced inflammation in the initiation and progression of atherosclerosis may be a potential mechanism for cerebral aneurysm formation and rupture.

\section{Cigarette Smoke and Hemodynamic Stress}

Hemodynamic forces, particularly wall sheer stress, play a key role in cerebral aneurysm development [50-52]. Accordingly, cerebral aneurysms are most commonly found at locations that are exposed to major hemodynamic forces, namely, at arterial bifurcations, junctions, or acute vascular angles. Hemodynamic insult has been shown to cause rapid degradation of the internal elastic lamina followed by thinning of the media and outward bulging of the vessel wall $[51,53,54]$. These changes appear to be mediated by several key components of the inflammatory response which are upregulated in response to hemodynamic stress, including nuclear factor $-\kappa \mathrm{B}(\mathrm{NF}-\kappa \mathrm{B})$, interleukin $1 \beta(\mathrm{IL} 1 \beta)$, nitric oxide (NO), and MMP $[12,15,54]$.

Wall shear stress is directly proportional to flow velocity and blood viscosity and inversely to arterial diameter. Thus,
CS can significantly increase wall shear stress, as it is known to increase blood viscosity and blood volume [7, 55]. Singh et al. [56] sought to elucidate the mechanisms by which cigarette smoking leads to cerebral aneurysm formation. Using a three-dimensional model, the authors elegantly demonstrated that smoking was associated with an incremental increase in wall shear stress at the site of aneurysm initiation (secondary to an increase in blood volume) and concluded that this finding could provide the missing link between CS exposure and aneurysm formation. Aside from increased blood viscosity and blood volume, CS may also raise wall shear stress by inducing cerebral vasoconstriction. The vasoconstrictive effects of CS and nicotine have been well documented and are usually attributed to the inhibition of eNOS and impaired NO signaling, a critical pathway for regulating cerebrovascular tone [57-59]. In a well-conducted study, Gerzanich et al. [60] found that chronic nicotine exposure blunts cerebral vasodilation by $\mathrm{NO}$ and demonstrated that the underlying mechanism involved a blockade of normal NO-mediated downregulation of calcium channels in cerebral VSMC.

The endothelin system, a crucial pathway associated with hemodynamic stress, is another possible mechanism through which CS may lead to aneurysm formation. The expression of endothelin type $\mathrm{B}$ receptors in response to mechanical stretch plays a critical role in cerebral aneurysm pathogenesis, and its inhibition was shown to suppress aneurysm progression [61-63]. Indeed, CS directly upregulates endothelin type $B$ receptors in cerebral arteries through activation of key intracellular inflammatory signal molecules, namely, mitogen-activated protein kinases (MAPK) and the NF- $\kappa \mathrm{B}$ signal pathway $[64,65]$.

Collectively, these data suggest a close relationship between CS exposure, hemodynamic stress, and the downstream inflammatory reaction leading to cerebral aneurysm development.

\section{Cigarette Smoke and Endothelial Dysfunction}

Endothelial dysfunction is a hallmark of cerebral aneurysm biology [15, 66-68]. The endothelium responds to hemodynamic stress with a series of physiological changes that increase its procoagulant and vasoconstrictive properties, leukocyte adhesion/migration, and the production of cytokines and growth factors. Using vascular corrosion casts, Jamous et al. [54] demonstrated that changes in the morphological characteristics of endothelial cells were the earliest changes in the process of aneurysm formation. Later, the same group added that endothelial cell injury, as evidenced by the loss of eNOS expression at the apical intimal pad, was the earliest pathological change in the process, triggering an inflammatory reaction characterized by macrophage infiltration, proliferation of VSMC, and proteolytic degradation of the vessel wall [12]. Along these lines, Tada et al. [67] noted early endothelial damage with interendothelial gaps at the site of cerebral aneurysm and demonstrated that the disruption of endothelial tight 
junctions was associated with the migration of macrophages into aneurysm walls. Aoki et al. [69, 70] brought further evidence of the critical role of endothelial dysfunction in CA formation, reporting several key changes in endothelial cells in response to high shear stress, including increased activity of NF- $\kappa \mathrm{B}$, monocyte chemoattractant protein-1(MCP-1), and prostaglandin E2 pathway.

The ability of CS to induce endothelial dysfunction in cerebral arteries has been well documented [48, 65, 71-74]. Lipid-soluble smoke particles are toxic to cultured endothelial cells and reduce endothelium-dependent relaxation in cerebral arteries [59, 72, 73, 75]. Likewise, CS was shown to induce endothelial apoptosis by activating caspase-3 [76]. CS-induced endothelial dysfunction seems to be primarily caused by accelerated inactivation of NO (an important vasodilator substance critical to the normal homeostasis of the endothelium) due to increased production of ROS [71]. The mechanism appears to involve several key enzyme systems, including NADH/NADPH oxidase and xanthine oxidase, both of which significantly contribute to ROS formation [71, 77-79]. As such, Fang et al. [78] showed that impairment of NO-dependent vasodilatation in cerebral arteries of nicotine-treated rats was caused by the increased formation of superoxide anions and noted reversal of these changes after inhibition of NADPH oxidase by apocynin. Elevated C-reactive protein (CRP) levels caused by CS can also promote endothelial dysfunction by lowering the production of $\mathrm{NO}$ and reducing its bioactivity [80]. Aside from the NO system, CS-induced endothelial dysfunction may also involve the angiotensin (AT) system, as AT1-receptor blockade was found to prevent CS-related impairment of endotheliumdependent vasodilation [81].

Endothelial NO synthase (eNOS) protects arterial walls from vascular inflammation by relieving hemodynamic stress via NO production [82]. Based upon this premise, Aoki et al. [83] examined the role eNOS in cerebral aneurysm pathogenesis and reported a protective role of eNOS against aneurysm formation and cerebrovascular inflammation. Importantly, nicotine in CS was shown to suppress this protective role of eNOS through the production of superoxide anions [84, 85]. Moreover, CS increases the expression of inducible NOS (iNOS) [86], which is activated in response to inflammatory stimuli and contributes to various inflammatory diseases [82]. This is particularly important with regard to cerebral aneurysm because induction of iNOS is associated with an increase in aneurysm size and apoptotic cell death [87]. Similarly, suppression of iNOS with aminoguanidine, a relatively selective inhibitor of iNOS, was shown to decrease the incidence of aneurysms in rats [88]. Thus, it appears that CS can affect cerebral aneurysm formation and progression by modulating the expression of key endothelial enzymes involved in cerebrovascular inflammation.

The proinflammatory activity of CS at the endothelial level further extends to the expression of several vascular adhesion molecules by endothelial cells that promote the adherence of circulating inflammatory cells to the luminal endothelial surface followed by their migration and the resultant vascular inflammatory response $[89,90]$. Moreover, nicotine was shown to affect endothelial tight junctions by decreasing the expression of ZO-1, occludin, cadherin, and adherent junctional proteins [91, 92] which, as discussed above, leads to the migration of macrophages and other inflammatory cells into cerebral aneurysm walls. Lastly, increased levels of matrix-degrading and proinflammatory changes including chemokines, cytokines, and STAT3 (inflammatory regulator) have been found in endothelial cells exposed to CS [89, 90, 93-95]. Taken together, experimental studies demonstrate that CS induces a proinflammatory activation of brain endothelial cells, disrupting their normal function and initiating CA formation.

\section{Effect of Cigarette Smoke on VSMC}

A solid body of evidence suggests that VSMC constitute an integral part of the pathways leading to cerebral aneurysm formation and rupture. As in atherosclerosis, VSMC migrate into the intima of cerebral aneurysm walls where they proliferate and produce myointimal hyperplasia $[38,96]$. More importantly, VSMC undergo a phenotypic modulation from a differentiated phenotype concerned primarily with contraction (characterized by expression of contractile genes/proteins such as smooth muscle-myosin heavy chain (SM-MHC) and smooth muscle- $\alpha$-actin) to a proinflammatory/promatrix remodeling phenotype characterized by the increased expression of cytokines, MMP, and ROS [9799]. This phenotypic modulation is mediated, at least in part, by the transcription factor KLF4 [100], and seems to occur under the influence of various inflammatory stimuli including interleukin-1b (IL-1b) [101], platelet-derived growth factor (PDGF) [102], oxidized phospholipids [103], tumor necrosis factor- $\alpha$ (TNF- $\alpha)$ [104], Ets-1 [105], and AT II [106]. A later event involves the loss of VSMC from cerebral aneurysm walls with resultant thinning of the media and aneurysm rupture.

CS was shown to promote several of the above-described changes involving VSMC. Several studies have reported that CS exhibits a direct effect on VSMC chemotaxis and proliferation [107-112]. As such, Chen et al. [113] demonstrated that CS extract promotes human VSMC proliferation as well as the expression of adhesion molecules and IL- 6 through a $\mathrm{NF}-\kappa \mathrm{B}$-dependent pathway. We have investigated the role of CS in producing phenotypic modulation and inflammation in cerebral VSMC in rats [86]. We found that CS directly produced marked phenotypic modulation with decreased expression of VSMC marker genes and myocardin while markedly increasing expression of inflammatory/matrix remodeling genes (MMP, MCP-1, IL- 1 , and TNF- $\alpha$ expression). Selective inhibition of KLF4 reversed this profound phenotypic modulation, highlighting the pivotal role of KLF4 in this process. These observations provided crucial evidence of a direct role of CS in the phenotypic modulation of VSMC in the walls of cerebral aneurysms. Lastly, CS extract was shown to be toxic to cerebral VSMC through calcium-induced cell injury and cell death from upregulation of VSMC calcium channels as elegantly demonstrated by Gerzanich et al. [60] in cerebral arterioles of rats. Collectively, these data indicate that the early and late changes exhibited 


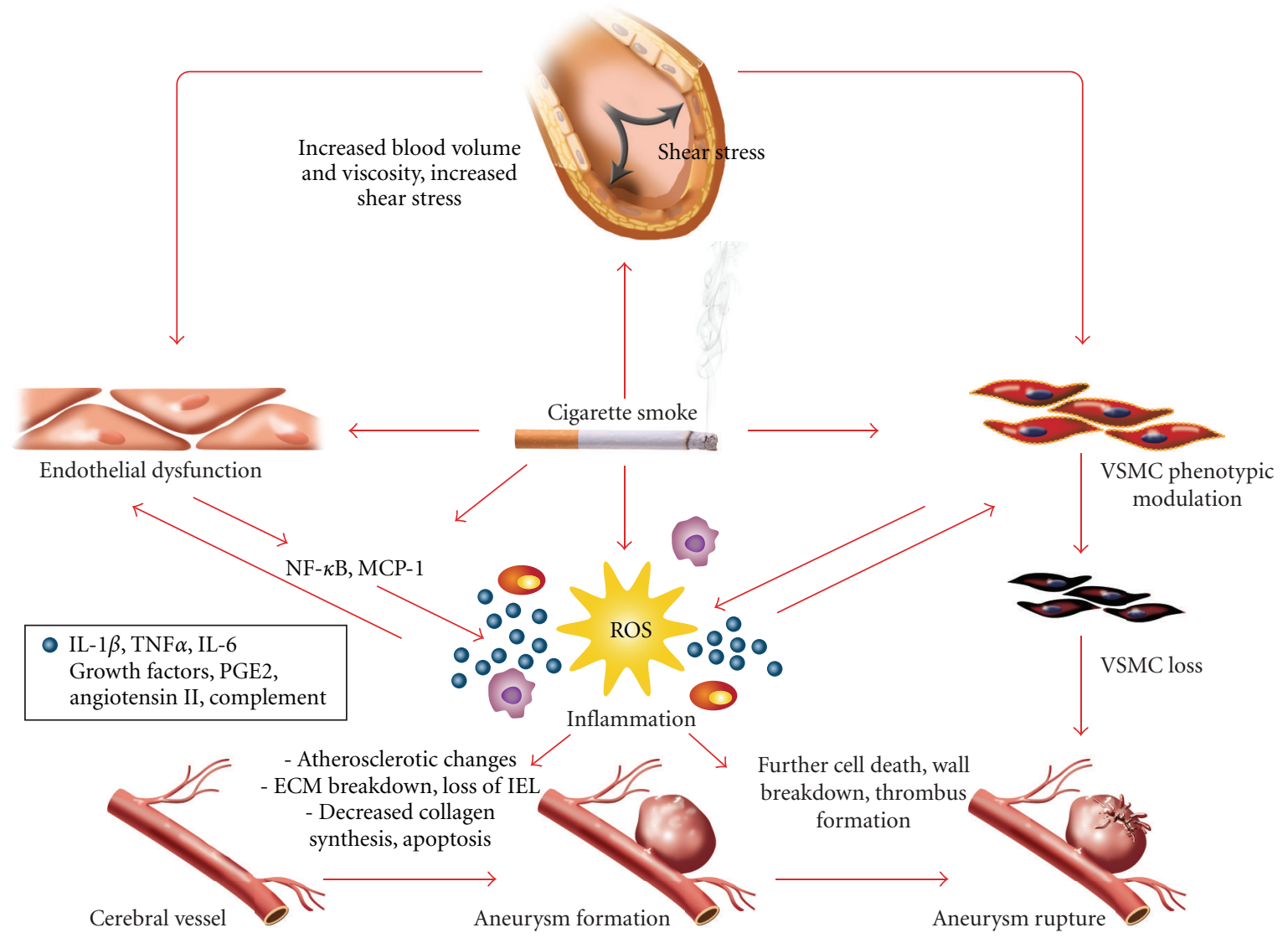

FIGURE 1: CS-associated inflammatory response in CA walls. CS increases wall shear stress in cerebral vessels and causes endothelial dysfunction with VSMC proinflammatory phenotypic modulation. The resultant inflammatory response implicates several inflammatory cells and mediators (ROS in particular) and leads to extracellular matrix remodeling and subsequent aneurysm formation. Further CSinduced matrix breakdown, cell death, and formation of an organizing thrombus eventually culminate in CA rupture. IEL: internal elastic lamina.

by VSMC during cerebral aneurysm formation, progression, and rupture are at least partly triggered by CS exposure.

\section{Cigarette Smoke and Inflammatory Mediators}

Several cytokines are increased in response to CS exposure [89, 114-119]. Specifically, smokers have higher levels of IL$1 \beta$, TNF $\alpha$, and IL-6 $[89,114-120]$, all of which significantly contribute to the pathobiology of cerebral aneurysm. In fact, IL- $1 \beta$ is thought to be a key inflammatory mediator in cerebral aneurysm as disruption of the IL-1 gene decreased the incidence of mature aneurysms in a mouse model [121]. IL1 $\beta$ acts primarily through activation of $N F-\kappa B$ in VSMC of cerebral aneurysm, reducing the biosynthesis of collagen and promoting apoptotic cell death [121, 122]. Likewise, TNF $\alpha$ was shown to induce apoptosis of VSMC in cerebral aneurysm walls while also activating MMP and vessel wall degradation [123-125]. IL-6 may also have an important role in cerebral aneurysm pathogenesis according to several genetic case-control studies. A recent meta-analysis of 8 genes and 13 polymorphisms in approximately 20,000 individuals found a strong association between IL-6 gene polymorphism and cerebral aneurysm [126].

Another mechanism through which CS may induce/amplify the inflammatory reaction in cerebral aneurysm walls is through the modulation of NF- $\kappa \mathrm{B}$ expression. As such, increased activation of NF- $\kappa$ B and its downstream inflammatory pathways were found in endothelial cells [89], VSMC [65, 113], and mononuclear cells [127] of smokers. $\mathrm{NF}-\kappa \mathrm{B}$ activation is followed by increased expression of adhesion molecules, migration of leukocytes (macrophages in particular), and increased degradation of the ECM [65, $69,89,113,127]$. In a study by Aoki et al. [69], NF- $\kappa \mathrm{B}$ was activated in cerebral arterial walls in the early stage of aneurysm formation with upregulated expression of downstream genes, and its selective inhibition prevented macrophage infiltration and aneurysm formation. Thus, NF$\kappa \mathrm{B}$, a seemingly important target of CS, plays a crucial role in the initiation of cerebral aneurysm development by inducing inflammatory genes related to macrophage recruitment and activation. Another critical regulator of 
TABLE 1: Summary of major pathways and inflammatory mediators affected by cigarette smoke exposure and involved in aneurysm formation.

\begin{tabular}{|c|c|}
\hline Major pathways & Major inflammatory mediators \\
\hline \multirow{9}{*}{ Atherosclerosis } & Oxidized LDL \\
\hline & NO \\
\hline & MCP1 \\
\hline & $\operatorname{IL} 1 \beta$ \\
\hline & ROS \\
\hline & TNF $\alpha$ \\
\hline & IL1 $\beta$, IL-6 \\
\hline & Growth factors \\
\hline & Selectins and adhesion molecules \\
\hline \multirow{3}{*}{ Hemodynamic stress (cerebral vasoconstriction, increased blood viscosity, and volume) } & eNOS \\
\hline & Endothelin type B receptors \\
\hline & $\mathrm{NF}-\kappa \mathrm{B}$ \\
\hline \multirow{8}{*}{ Endothelial dysfunction } & $\mathrm{NO}$ \\
\hline & ROS \\
\hline & CRP \\
\hline & Angiotensin \\
\hline & eNOS \\
\hline & iNOS \\
\hline & Several chemokines and cytokines \\
\hline & STAT3 \\
\hline \multirow{3}{*}{ VSMC proinflammatory, promatrix remodeling phenotypic modulation, apoptotic cell death } & $\mathrm{NF}-\kappa \mathrm{B}$ \\
\hline & KLF4 \\
\hline & Calcium channels \\
\hline \multirow{7}{*}{ Chronic inflammatory reaction, vessel wall remodeling and damage, apoptotic cell death } & IL- $1 \beta$, TNF $\alpha$, and IL-6 \\
\hline & NF- $\kappa \mathrm{B}$ \\
\hline & MMP and TIMP \\
\hline & MCP-1 \\
\hline & MAPK \\
\hline & ROS \\
\hline & NO \\
\hline
\end{tabular}

macrophage activation in cerebral aneurysms, also induced by CS, is MCP-1 [86, 128-131]. The importance of this factor was highlighted in animal studies where knockout of MCP1 led to decreased CA formation, decreased macrophage infiltration, and decreased expression of MMP [128, 129].

There is a close relationship between CS exposure, macrophage activation, and MMP release. Indeed, Hossain et al. [89] found that CS induces macrophage differentiation in cerebral arteries with a marked enhancement in the release of IL- $1 \beta$, TNF- $\alpha$, and MMP-2/9. Likewise, increased levels of MMP and macrophages along with decreased levels of tissue inhibitor of metalloproteinases (TIMP) and elastin were found in carotid vessels of smokers as compared to nonsmokers [132]. Similarly, Vikman et al. [133] observed enhanced expression of MMP13 in CS-exposed cerebral arteries through activation of the MAPK inflammatory signaling pathway. We have also demonstrated that CS extract stimulates MMP in rat cerebral VSMC in vitro and in carotid smooth muscle cells in vivo [86]. This increased activity of MMP could well explain the higher incidence of SAH in smokers, as degradation of the ECM by MMP (which weakens the aneurysm wall) is indisputably a key event in cerebral aneurysm rupture $[15,20,134]$. Accordingly, serum MMP-9 levels increase in SAH patients and normalize by day 12 after-SAH, suggesting an intimate relationship between MMP-9 and aneurysm rupture [135]. Indeed, plasma MMP9 is mainly dependent on neutrophil release (gelatinase granules) in human, and neutrophil serine protease release is one of the main determinants of aneurysmal rupture [136]. The inappropriate activation of MMP in cerebral arteries is not the only mechanism through which CS leads to cerebral aneurysm wall fragility. In fact, CS reduces the expression of prolyl-4-hydroxylase, a key enzyme in arterial wall collagen metabolism, resulting in reduced collagen synthesis and a thin vulnerable aneurysm wall [137]. Taken together, these data indicate that CS activates key inflammatory mediators 
that lead to macrophage activation, release of MMP, and decreased collagen synthesis, ultimately resulting in cerebral aneurysm thinning and rupture.

\section{ROS and Cigarette Smoke}

ROS are a major mediator of various inflammatory cascades. Free radical-mediated oxidative stress is thought to be a pivotal step for the development of cerebral aneurysm. In a wellconducted animal study by Aoki et al. [138], ROS-producing gene, p47phox, was upregulated in infiltrating macrophages with suppression of ROS-eliminating genes, suggesting that ROS overproduction occurred in aneurysm walls. Furthermore, cerebral aneurysm formation and inflammation in aneurysm walls were markedly suppressed by $\mathrm{p} 47$ phox gene deletion or edaravone, a powerful free radical scavenger. As discussed above, CS is a major source of free radicals which could arise from (a) the gas or tar phase of CS, (b)circulating or in situ-activated leukocytes, and (c) endogenous sources of ROS, that is, uncoupled eNOS, xanthine oxidase, and the mitochondrial electron transport chain [48, 139]. Many of the abnormalities observed in cerebral aneurysm including endothelial dysfunction, proinflammatory reactions, adhesion molecule expression, VSMC proliferation, apoptosis, MMP activation, and tissue destruction may be at least partly explained by the effects of increased oxidative stress $[8,45$, 140-142]. Accordingly, antioxidants have been shown to improve or reverse the proinflammatory attributes associated with CS [143-145]. Thus, ROS may constitute an integral part of the inflammatory reaction leading to CA formation and rupture in smokers.

\section{Cigarette Smoke and Thrombosis}

CS predisposes to systemic and cerebral thrombosis [146148]. Nicotine increases plasminogen activator inhibitor-1 via protein kinase $\mathrm{C}$ dependant pathway in human brainderived endothelial cells [147]. Additionally, increased levels of tissue factor (TF), a key factor in thrombogenesis, and decreased levels of TF pathway inhibitor-1 are associated with CS $[149,150]$. This predisposition to thrombosis is particularly relevant with regard to cerebral aneurysm because the presence of an organizing luminal thrombus was identified as a predictor of aneurysm rupture [15, 145]. Likewise, partial or total deendothelialization, a prerequisite for thrombus formation, is intimately associated with human cerebral aneurysm rupture $[13,16]$. In fact, following endothelial injury and deendothelialization (from CS, hemodynamic stress, etc.), exposure of subendothelial prothrombotic structures initiates a coagulation cascade that leads to thrombus formation. Subsequently, erythrocytes and platelets become trapped in the fibrin meshwork with expression of chemotactic factors and macrophage/neutrophils infiltration [15]. Erythrocyte lysis, complement activation, and oxidative stress ultimately result in further breakdown of the cerebral aneurysm wall by MMP $[15,151]$. Thus, by promoting the formation of a luminal thrombus, CS may further amplify the inflammatory and destructive reaction in aneurysmal walls predisposing to aneurysm rupture.

\section{Conclusion}

There is a complex yet interesting interplay between CS exposure, vascular inflammation, and cerebral aneurysm formation and rupture. CS appears to affect every step in the cascade of events leading to SAH from hemodynamic stress and endothelial dysfunction to aneurysm wall weakening and rupture (Figure 1, Table 1). The mechanisms described in this paper could explain why smokers are at increased risk of SAH. Further characterization of the role of CS-induced inflammation in cerebral aneurysm is needed to fill the considerable gaps in our current knowledge. Such knowledge could pave the way for the development of future targeted therapy.

\section{Conflict of Interest}

The authors declared that there is no conflict of interests.

\section{Authors' Contribution}

N. Chalouhi and M. S. Ali contributed equally to this work.

\section{Acknowledgments}

The authors would like to thank Mr. Paul Schiffmacher for his elegant work on the illustration. This work was supported by the Joseph and Marie Field Cerebrovascular Research Laboratory Endowment and by the National Institute of Neurological Disorders and Stroke (1K08NS067072 to A. S. Dumont).

\section{References}

[1] R. Talhout, T. Schulz, E. Florek, J. van Benthem, P. Wester, and A. Opperhuizen, "Hazardous compounds in tobacco smoke," International Journal of Environmental Research and Public Health, vol. 8, no. 2, pp. 613-628, 2011.

[2] D. J. Nieuwkamp, L. E. Setz, A. Algra, F. H. Linn, N. K. de Rooij, and G. J. Rinkel, "Changes in case fatality of aneurysmal subarachnoid haemorrhage over time, according to age, sex, and region: a meta-analysis," The Lancet Neurology, vol. 8, no. 7, pp. 635-642, 2009.

[3] D. O. Wiebers, J. P. Whisnant, J. Huston III et al., "Unruptured intracranial aneurysms: natural history, clinical outcome, and risks of surgical and endovascular treatment," The Lancet, vol. 362, no. 9378, pp. 103-110, 2003.

[4] N. Chalouhi, R. Chitale, P. Jabbour et al., "The case for family screening for intracranial aneurysms," Neurosurgical Focus, vol. 31, no. 6, Article ID E8, 2011.

[5] D. Woo, J. Khoury, M. M. Haverbusch et al., "Smoking and family history and risk of aneurysmal subarachnoid hemorrhage," Neurology, vol. 72, no. 1, pp. 69-72, 2009.

[6] Y. Arnson, Y. Shoenfeld, and H. Amital, "Effects of tobacco smoke on immunity, inflammation and autoimmunity," Journal of Autoimmunity, vol. 34, no. 3, pp. J258-J265, 2010. 
[7] P. Mazzone, W. Tierney, M. Hossain, V. Puvenna, D. Janigro, and L. Cucullo, "Pathophysiological impact of cigarette smoke exposure on the cerebrovascular system with a focus on the blood-brain barrier: expanding the awareness of smoking toxicity in an underappreciated area," International Journal of Environmental Research and Public Health, vol. 7, no. 12, pp. 4111-4126, 2010.

[8] W. A. Pryor, K. Stone, C. E. Cross, L. Machlin, and L. Packer, "Oxidants in cigarette smoke: radicals, hydrogen peroxide, peroxynitrate, and peroxynitrite," Annals of the New York Academy of Sciences, vol. 686, pp. 12-28, 1993.

[9] S. A. Glantz and W. W. Parmley, "Passive smoking and heart disease. Epidemiology, physiology, and biochemistry," Circulation, vol. 83, no. 1, pp. 1-12, 1991.

[10] R. Bonita, J. Duncan, T. Truelsen, R. T. Jackson, and R. Beaglehole, "Passive smoking as well as active smoking increases the risk of acute stroke," Tobacco Control, vol. 8, no. 2, pp. 156-160, 1999.

[11] C. S. Anderson, V. Feigin, D. Bennett, R. B. Lin, G. Hankey, and K. Jamrozik, "Active and passive smoking and the risk of subarachnoid hemorrhage: an international populationbased case-control study," Stroke, vol. 35, no. 3, pp. 633-637, 2004.

[12] M. A. Jamous, S. Nagahiro, K. T. Kitazato et al., "Endothelial injury and inflammatory response induced by hemodynamic changes preceding intracranial aneurysm formation: experimental study in rats," Journal of Neurosurgery, vol. 107, no. 2, pp. 405-411, 2007.

[13] K. Kataoka, M. Taneda, T. Asai, A. Kinoshita, M. Ito, and R. Kuroda, "Structural fragility and inflammatory response of ruptured cerebral aneurysms: a comparative study between ruptured and unruptured cerebral aneurysms," Stroke, vol. 30, no. 7, pp. 1396-1401, 1999.

[14] A. M. Nixon, M. Gunel, and B. E. Sumpio, "The critical role of hemodynamics in the development of cerebral vascular disease: a review," Journal of Neurosurgery, vol. 112, no. 6, pp. 1240-1253, 2010.

[15] R. Tulamo, J. Frösen, J. Hernesniemi, and M. Niemelä, "Inflammatory changes in the aneurysm wall: a review," Journal of NeuroInterventional Surgery, vol. 2, no. 2, pp. 120 $130,2010$.

[16] J. Frösen, A. Piippo, A. Paetau et al., "Remodeling of saccular cerebral artery aneurysm wall is associated with rupture: histological analysis of 24 unruptured and 42 ruptured cases," Stroke, vol. 35, no. 10, pp. 2287-2293, 2004.

[17] T. Aoki, H. Kataoka, M. Morimoto, K. Nozaki, and N. Hashimoto, "Macrophage-derived matrix metalloproteinase-2 and -9 promote the progression of cerebral aneurysms in rats," Stroke, vol. 38, no. 1, pp. 162-169, 2007.

[18] T. Aoki, H. Kataoka, T. Moriwaki, K. Nozaki, and N. Hashimoto, "Role of TIMP-1 and TIMP-2 in the progression of cerebral aneurysms," Stroke, vol. 38, no. 8, pp. 2337-2345, 2007.

[19] Y. Takemura, Y. Hirata, N. Sakata, K. Nabeshima, M. Takeshita, and T. Inoue, "Histopathologic characteristics of a saccular aneurysm arising in the non-branching segment of the distal middle cerebral artery," Pathology Research and Practice, vol. 206, no. 6, pp. 391-396, 2010.

[20] D. Jin, J. Sheng, X. Yang, and B. Gao, "Matrix metalloproteinases and tissue inhibitors of metalloproteinases expression in human cerebral ruptured and unruptured aneurysm," Surgical Neurology, vol. 68, supplement 2, no. 6, pp. S11-S16, 2007.
[21] G. J. E. Rinkel, M. Djibuti, A. Algra, and J. Van Gijn, "Prevalence and risk of rupture of intracranial aneurysms: a systematic review," Stroke, vol. 29, no. 1, pp. 251-256, 1998.

[22] B. V. Nahed, M. Bydon, A. K. Ozturk, K. Bilguvar, F. Bayrakli, and M. Gunel, "Genetics of intracranial aneurysms," Neurosurgery, vol. 60, no. 2, pp. 213-225, 2007.

[23] J. Chen, Y. Zhu, Y. Jiang et al., "A functional variant of the collagen type III alphal gene modify risk of sporadic intracranial aneurysms," Human Genetics, vol. 131, no. 7, pp. 1137-1143, 2012.

[24] H. Onda, H. Kasuya, T. Yoneyama et al., "Genomewidelinkage and haplotype-association studies map intracranial aneurysm to chromosome 7q11," American Journal of Human Genetics, vol. 69, no. 4, pp. 804-819, 2001.

[25] Y. M. Ruigrok, G. J. E. Rinkel, A. Algra, T. W. M. Raaymakers, and J. Van Gijn, "Characteristics of intracranial aneurysms in patients with familial subarachnoid hemorrhage," Neurology, vol. 62, no. 6, pp. 891-894, 2004.

[26] K. Yasuno, M. Bakircioglu, S. K. Low et al., "Common variant near the endothelin receptor type A, (EDNRA) gene is associated with intracranial aneurysm risk," Proceedings of the National Academy of Sciences of the United States of America, vol. 108, no. 49, pp. 19707-19712, 2011.

[27] V. G. Khurana, I. Meissner, Y. R. Sohni et al., "The presence of tandem endothelial nitric oxide synthase gene polymorphisms identifying brain aneurysms more prone to rupture," Journal of Neurosurgery, vol. 102, no. 3, pp. 526-531, 2005.

[28] Y. M. Ruigrok, S. Tan, J. Medic, G. J. E. Rinkel, and C. Wijmenga, "Genes involved in the transforming growth factor beta signalling pathway and the risk of intracranial aneurysms," Journal of Neurology, Neurosurgery and Psychiatry, vol. 79, no. 6, pp. 722-724, 2008.

[29] H. Akagawa, H. Kasuya, H. Onda et al., "Influence of endothelial nitric oxide synthase T-786C single nucleotide polymorphism on aneurysm size," Journal of Neurosurgery, vol. 102, no. 1, pp. 68-71, 2005.

[30] T. G. Kim, N. K. Kim, M. J. Baek et al., "The relationships between endothelial nitric oxide synthase polymorphisms and the formation of intracranial aneurysms in the Korean population," Neurosurgical Focus, vol. 30, no. 6, Article ID E23, 2011.

[31] R. Deka, D. L. Koller, D. Lai et al., "The relationship between smoking and replicated sequence variants on chromosomes 8 and 9 with familial intracranial aneurysm," Stroke, vol. 41, no. 6, pp. 1132-1137, 2010.

[32] N. Chalouhi, A. S. Dumont, C. Randazzo et al., "Management of incidentally discovered intracranial vascular abnormalities," Neurosurgical Focus, vol. 31, no. 6, Article ID E1, 2011.

[33] V. L. Feigin, G. J. E. Rinkel, C. M. M. Lawes et al., "Risk factors for subarachnoid hemorrhage: an updated systematic review of epidemiological studies," Stroke, vol. 36, no. 12, pp. 27732780, 2005.

[34] M. H. M. Vlak, G. J. E. Rinkel, P. Greebe, J. G. Van Der Bom, and A. Algra, "Trigger factors and their attributable risk for rupture of intracranial aneurysms: a case-crossover study," Stroke, vol. 42, no. 7, pp. 1878-1882, 2011.

[35] I. Shiue, H. Arima, G. J. Hankey, and C. S. Anderson, "Dietary intake of key nutrients and subarachnoid hemorrhage: a population-based case-control study in Australasia," Cerebrovascular Diseases, vol. 31, no. 5, pp. 464-470, 2011.

[36] K. Okamoto and R. Horisawa, "Dietary antioxidant intake and risk of an aneurysmal rupture subarachnoid hemorrhage 
in Japan," European Journal of Clinical Nutrition, vol. 61, no. 9, pp. 1140-1142, 2007.

[37] K. Okamoto and R. Horisawa, "Soy products and risk of an aneurysmal rupture subarachnoid hemorrhage in Japan," European Journal of Cardiovascular Prevention and Rehabilitation, vol. 13, no. 2, pp. 284-287, 2006.

[38] T. A. Kosierkiewicz, S. M. Factor, and D. W. Dickson, "Immunocytochemical studies of atherosclerotic lesions of cerebral berry aneurysms," Journal of Neuropathology and Experimental Neurology, vol. 53, no. 4, pp. 399-406, 1994.

[39] M. Killer-Oberpfalzer, M. Aichholzer, S. Weis et al., "Histological analysis of clipped human intracranial aneurysms and parent arteries with short-term follow-up," Cardiovascular Pathology, vol. 21, no. 4, pp. 299-306, 2012.

[40] J. Adamson, S. E. Humphries, J. R. Ostergaard, B. Voldby, P. Richards, and J. T. Powell, "Are cerebral aneurysms atherosclerotic?” Stroke, vol. 25, no. 5, pp. 963-966, 1994.

[41] R. M. Greenhalgh, S. Laing, and G. W. Taylor, "Risk factors in carotid artery stenosis and intracranial aneurysms," Journal of Cardiovascular Surgery, vol. 21, no. 5, pp. 559-567, 1980.

[42] I. M. Nordon, R. J. Hinchliffe, P. J. Holt, I. M. Loftus, and M. W. Thompson, "Review of current theories for abdominal aortic aneurysm pathogenesis," Vascular, vol. 17, no. 5, pp. 253-263, 2009.

[43] C. Xu, C. K. Zarins, and S. Glagov, "Aneurysmal and occlusive atherosclerosis of the human abdominal aorta," Journal of Vascular Surgery, vol. 33, no. 1, pp. 91-96, 2001.

[44] D. Reed, C. Reed, G. Stemmermann, and T. Hayashi, "Are aortic aneurysms caused by atherosclerosis?" Circulation, vol. 85, no. 1, pp. 205-211, 1992.

[45] D. Harrison, K. K. Griendling, U. Landmesser, B. Hornig, and H. Drexler, "Role of oxidative stress in atherosclerosis," American Journal of Cardiology, vol. 91, no. 3, 2003.

[46] R. Ross, "Atherosclerosis-an inflammatory disease," New England Journal of Medicine, vol. 340, no. 2, pp. 115-126, 1999.

[47] N. R. Madamanchi, A. Vendrov, and M. S. Runge, "Oxidative stress and vascular disease," Arteriosclerosis, Thrombosis, and Vascular Biology, vol. 25, no. 1, pp. 29-38, 2005.

[48] J. A. Ambrose and R. S. Barua, "The pathophysiology of cigarette smoking and cardiovascular disease: an update," Journal of the American College of Cardiology, vol. 43, no. 10, pp. 1731-1737, 2004.

[49] N. L. Benowitz, "Cigarette smoking and cardiovascular disease: pathophysiology and implications for treatment," Progress in Cardiovascular Diseases, vol. 46, no. 1, pp. 91-111, 2003.

[50] T. Hashimoto, H. Meng, and W. L. Young, "Intracranial aneurysms: links among inflammation, hemodynamics and vascular remodeling," Neurological Research, vol. 28, no. 4, pp. 372-380, 2006.

[51] H. Meng, E. Metaxa, L. Gao et al., "Progressive aneurysm development following hemodynamic insult: laboratory investigation," Journal of Neurosurgery, vol. 114, no. 4, pp. 1095-1103, 2011.

[52] E. Sho, M. Sho, T. M. Singh et al., "Arterial enlargement in response to high flow requires early expression of matrix metalloproteinases to degrade extracellular matrix," Experimental and Molecular Pathology, vol. 73, no. 2, pp. 142-153, 2002.

[53] N. Sakamoto, T. Ohashi, and M. Sato, "Effect of fluid shear stress on migration of vascular smooth muscle cells in cocultured model," Annals of Biomedical Engineering, vol. 34, no. 3, pp. 408-415, 2006.
[54] M. A. Jamous, S. Nagahiro, K. T. Kitazato, K. Satoh, and J. Satomi, "Vascular corrosion casts mirroring early morphological changes that lead to the formation of saccular cerebral aneurysm: an experimental study in rats," Journal of Neurosurgery, vol. 102, no. 3, pp. 532-535, 2005.

[55] J. F. Price, P. I. Mowbray, A. J. Lee, A. Rumley, G. D. O. Lowe, and F. G. R. Fowkes, "Relationship between smoking and cardiovascular risk factors in the development of peripheral arterial disease and coronary artery disease. Edinburgh Artery Study," European Heart Journal, vol. 20, no. 5, pp. 344353, 1999.

[56] P. K. Singh, A. Marzo, B. Howard et al., "Effects of smoking and hypertension on wall shear stress and oscillatory shear index at the site of intracranial aneurysm formation," Clinical Neurology and Neurosurgery, vol. 112, no. 4, pp. 306-313, 2010.

[57] W. G. Mayhan and K. P. Patel, "Effect of nicotine on endothelium-dependent arteriolar dilatation in vivo," American Journal of Physiology-Heart and Circulatory Physiology, vol. 272, no. 5, pp. H2337-H2342, 1997.

[58] W. G. Mayhan, G. M. Sharpe, and P. Anding, "Agonistinduced release of nitric oxide during acute exposure to nicotine," Life Sciences, vol. 65, no. 17, pp. 1829-1837, 1999.

[59] M. Koide, S. Nishizawa, S. Yamamoto, M. Yamaguchi, H. Namba, and S. Terakawa, "Nicotine exposure, mimicked smoking, directly and indirectly enhanced protein kinase C activity in isolated canine basilar artery, resulting in enhancement of arterial contraction," Journal of Cerebral Blood Flow and Metabolism, vol. 25, pp. 292-301, 2005.

[60] V. Gerzanich, F. Zhang, G. A. West, and J. M. Simard, "Chronic nicotine alters NO signaling of $\mathrm{Ca}^{2+}$ channels in cerebral arterioles," Circulation Research, vol. 88, no. 3, pp. 359-365, 2001.

[61] N. Sadamasa, K. Nozaki, Y. Takagi et al., "Cerebral aneurysm progression suppressed by blockage of endothelin B receptor," Journal of Neurosurgery, vol. 106, no. 2, pp. 330-336, 2007.

[62] M. Cattaruzza, C. Dimigen, H. Ehrenreich, and M. Hecker, "Stretch-induced endothelin B receptor-mediated apoptosis in vascular smooth muscle cells," FASEB Journal, vol. 14, no. 7, pp. 991-998, 2000.

[63] Y. Takagi, M. Ishikawa, K. Nozaki et al., "Increased expression of phosphorylated c-Jun amino-terminal kinase and phosphorylated c-Jun in human cerebral aneurysms: role of the c-Jun amino-terminal kinase/c-Jun pathway in apoptosis of vascular walls," Neurosurgery, vol. 51, no. 4, pp. 997-1004, 2002.

[64] H. Sandhu, C. B. Xu, and L. Edvinsson, "Upregulation of contractile endothelin type B receptors by lipid-soluble cigarette smoking particles in rat cerebral arteries via activation of MAPK," Toxicology and Applied Pharmacology, vol. 249, no. 1, pp. 25-32, 2010.

[65] C. B. Xu, J. P. Zheng, W. Zhang, Y. Zhang, and L. Edvinsson, "Lipid-soluble smoke particles upregulate vascular smooth muscle ETB receptors via activation of mitogen-activating protein kinases and NF-kappaB pathways," Toxicological Sciences, vol. 106, no. 2, pp. 546-555, 2008.

[66] N. Sakamoto, N. Saito, X. Han, T. Ohashi, and M. Sato, "Effect of spatial gradient in fluid shear stress on morphological changes in endothelial cells in response to flow," Biochemical and Biophysical Research Communications, vol. 395, no. 2, pp. 264-269, 2010.

[67] Y. Tada, K. Yagi, K. T. Kitazato et al., "Reduction of endothelial tight junction proteins is related to cerebral aneurysm 
formation in rats," Journal of Hypertension, vol. 28, no. 9, pp. 1883-1891, 2010.

[68] Y. Tada, K. T. Kitazato, K. Yagi et al., "Statins promote the growth of experimentally induced cerebral aneurysms in estrogen-deficient rats," Stroke, vol. 42, no. 8, pp. 2286-2293, 2011.

[69] T. Aoki, H. Kataoka, M. Shimamura et al., "NF- $\kappa$ B is a key mediator of cerebral aneurysm formation," Circulation, vol. 116, no. 24, pp. 2830-2840, 2007.

[70] T. Aoki, M. Nishimura, T. Matsuoka et al., "PGE2-EP2 signalling in endothelium is activated by haemodynamic stress and induces cerebral aneurysm through an amplifying loop via NF- $\kappa \mathrm{B}$, , British Journal of Pharmacology, vol. 163, no. 6, pp. 1237-1249, 2011.

[71] H. Cai and D. G. Harrison, "Endothelial dysfunction in cardiovascular diseases: the role of oxidant stress," Circulation Research, vol. 87, no. 10, pp. 840-844, 2000.

[72] C. B. Xu, H. Pessah-Rasmussen, and L. Stavenow, "Interactions between cultured bovine arterial endothelial and smooth muscle cells: effects of injury on the release of growth stimulating and growth inhibiting substances," Pharmacology and Toxicology, vol. 69, no. 3, pp. 195-200, 1991.

[73] C. B. Xu, L. Stavenow, and H. Pessah-Rasmussen, "Interactions between cultured bovine arterial endothelial and smooth muscle cells; effects of modulated low density lipoproteins on cell proliferation and prostacyclin release," Scandinavian Journal of Clinical and Laboratory Investigation, vol. 54, no. 3, pp. 191-198, 1994.

[74] M. Iida, H. Iida, S. Dohi, M. Takenaka, and H. Fujiwara, "Mechanisms underlying cerebrovascular effects of cigarette smoking in rats in vivo," Stroke, vol. 29, no. 8, pp. 1656-1665, 1998.

[75] J. Y. Zhang, Y. X. Cao, C. B. Xu, and L. Edvinsson, "Lipidsoluble smoke particles damage endothelial cells and reduce endothelium-dependent dilatation in rat and man," BMC Cardiovascular Disorders, vol. 6, p. 3, 2006.

[76] M. Raveendran, J. Wang, D. Senthil et al., "Endogenous nitric oxide activation protects against cigarette smoking induced apoptosis in endothelial cells," FEBS Letters, vol. 579, no. 3, pp. 733-740, 2005.

[77] H. Iida, M. Iida, M. Takenake, N. Fukuoka, and S. Dobi, "Rho-kinase inhibitor and Nicotinamide Adenine Dinucleotide PHosphate oxidise inhibitor prevent impairment of endothelium-dependent cerebral vasodilation by acute cigarette smoking in rats," Journal of the Renin-AngiotensinAldosterone System, vol. 9, no. 2, pp. 89-94, 2008.

[78] Q. Fang, H. Sun, D. M. Arrick, and W. G. Mayhan, "Inhibition of NADPH oxidase improves impaired reactivity of pial arterioles during chronic exposure to nicotine," Journal of Applied Physiology, vol. 100, no. 2, pp. 631-636, 2006.

[79] Kh. M. Markov, "Oxidant stress and endothelial dysfunction," Patologicheskaia Fiziologiia i Eksperimental'naia Terapiia, no. 6, pp. 5-9, 2005.

[80] S. Verma, C. H. Wang, S. H. Li et al., "A self-fulfilling prophecy: C-reactive protein attenuates nitric oxide production and inhibits angiogenesis," Circulation, vol. 106, no. 8, pp. 913-919, 2002.

[81] H. Iida, M. Iida, M. Takenaka, H. Fujiwara, and S. Dohi, "Angiotensin II type 1 (AT1)-receptor blocker prevents impairment of endothelium-dependent cerebral vasodilation by acute cigarette smoking in rats," Life Sciences, vol. 78, no. 12, pp. 1310-1316, 2006.
[82] P. J. Andrew and B. Mayer, "Enzymatic function of nitric oxide synthases," Cardiovascular Research, vol. 43, no. 3, pp. 521-531, 1999.

[83] T. Aoki, M. Nishimura, H. Kataoka, R. Ishibashi, K. Nozaki, and S. Miyamoto, "Complementary inhibition of cerebral aneurysm formation by eNOS and nNOS," Laboratory Investigation, vol. 91, no. 4, pp. 619-626, 2011.

[84] Q. Fang, H. Sun, and W. G. Mayhan, "Impairment of nitric oxide synthase-dependent dilatation of cerebral arterioles during infusion of nicotine," American Journal of PhysiologyHeart and Circulatory Physiology, vol. 284, no. 2, pp. H528H534, 2003.

[85] N. Toda and H. Toda, "Nitric oxide-mediated blood flow regulation as affected by smoking and nicotine," European Journal of Pharmacology, vol. 649, no. 1-3, pp. 1-13, 2010.

[86] M. Ali, Z. Yu, P. Jabbour et al., "Cigarette smoke directly produces a pro-inflammatory/matrix remodeling phenotype in cerebral vascular smooth muscle cells via KLF4: a potential mechanism for cerebral aneurysm pathogenesis," Stroke, vol. 43, Article ID A112, 2012.

[87] N. Sadamasa, K. Nozaki, and N. Hashimoto, "Disruption of Gene for Inducible Nitric Oxide Synthase Reduces Progression of Cerebral Aneurysms," Stroke, vol. 34, no. 12, pp. 2980-2984, 2003.

[88] S. Fukuda, N. Hashimoto, H. Naritomi et al., "Prevention of rat cerebral aneurysm formation by inhibition of nitric oxide synthase," Circulation, vol. 101, no. 21, pp. 2532-2538, 2000.

[89] M. Hossain, T. Sathe, V. Fazio et al., "Tobacco smoke: a critical etiological factor for vascular impairment at the blood-brain barrier," Brain Research, vol. 1287, pp. 192-205, 2009.

[90] B. K. Nordskog, A. D. Blixt, W. T. Morgan, W. R. Fields, and G. M. Hellmann, "Matrix-degrading and pro-inflammatory changes in human vascular endothelial cells exposed to cigarette smoke condensate," Cardiovascular Toxicology, vol. 3, no. 2, pp. 101-117, 2003.

[91] T. J. Abbruscato, S. P. Lopez, K. S. Mark, B. T. Hawkins, and T. P. Davis, "Nicotine and cotinine modulate cerebral microvascular permeability and protein expression of ZO-1 through nicotinic acetylcholine receptors expressed on brain endothelial cells," Journal of Pharmaceutical Sciences, vol. 91, no. 12, pp. 2525-2538, 2002.

[92] P. Hutamekalin, A. E. Farkas, A. Orbók et al., "Effect of nicotine and polyaromtic hydrocarbons on cerebral endothelial cells," Cell Biology International, vol. 32, no. 2, pp. 198-209, 2008.

[93] M. Wang, W. Zhang, P. Crisostomo et al., "Endothelial STAT3 plays a critical role in generalized myocardial proinflammatory and proapoptotic signaling," American Journal of Physiology-Heart and Circulatory Physiology, vol. 293, no. 4, pp. H2101-H2108, 2007.

[94] A. Kano, M. J. Wolfgang, Q. Gao et al., "Endothelial Cells Require STAT3 for Protection against Endotoxin-induced Inflammation," Journal of Experimental Medicine, vol. 198, no. 10, pp. 1517-1525, 2003.

[95] V. Lemaitre, A. J. Dabo, and D. D’Armiento, “Cigarette smoke components induce matrix metalloproteinase-1 in aortic endothelial cells through inhibition of mTOR signaling," Society of Toxicology, vol. 123, no. 2, pp. 542-549, 2011.

[96] G. K. Owens, M. S. Kumar, and B. R. Wamhoff, "Molecular regulation of vascular smooth muscle cell differentiation in development and disease," Physiological Reviews, vol. 84, no. 3, pp. 767-801, 2004. 
[97] T. Kilic, M. Sohrabifar, O. Kurtkaya et al., "Expression of structural proteins and angiogenic factors in normal arterial and unruptured and ruptured aneurysm walls," Neurosurgery, vol. 57, no. 5, pp. 997-1006, 2005.

[98] J. Pera, M. Korostynski, T. Krzyszkowski et al., "Gene expression profiles in human ruptured and unruptured intracranial aneurysms: what is the role of inflammation?" Stroke, vol. 41, no. 2, pp. 224-231, 2010.

[99] I. Sibon, N. Mercier, D. Darret, P. Lacolley, and J. M. D. Lamazière, "Association between semicarbazide-sensitive amine oxidase, a regulator of the glucose transporter, and elastic lamellae thinning during experimental cerebral aneurysm development: laboratory investigation," Journal of Neurosurgery, vol. 108, no. 3, pp. 558-566, 2008.

[100] T. Yoshida, Q. Gan, and G. K. Owens, "Krüppel-like factor 4, Elk-1, and histone deacetylases cooperatively suppress smooth muscle cell differentiation markers in response to oxidized phospholipids," American Journal of Physiology-Cell Physiology, vol. 295, no. 5, pp. C1175-C1182, 2008.

[101] M. R. Alexander, M. Murgai, C. W. Moehle, and G. K. Owens, "Interleukin-1beta modulates smooth muscle cell phenotype to a distinct inflammatory state relative to PDGFDD via NF-kappaB-dependent mechanisms," Physiological Genomics, vol. 44, no. 7, pp. 417-429, 2012.

[102] T. Yoshida, Q. Gan, Y. Shang, and G. K. Owens, "Plateletderived growth factor-BB represses smooth muscle cell marker genes via changes in binding of MKL factors and histone deacetylases to their promoters," American Journal of Physiology-Cell Physiology, vol. 292, no. 2, pp. C886-C895, 2007.

[103] N. A. Pidkovka, O. A. Cherepanova, T. Yoshida et al., "Oxidized phospholipids induce phenotypic switching of vascular smooth muscle cells in vivo and in vitro," Circulation Research, vol. 101, no. 8, pp. 792-801, 2007.

[104] M. Ali, Z. Yu, P. Jabbour et al., "Tumor necrosis factor-alpha induces phenotypic modulation in cerebral vascular smooth muscle cells via KLF4: implications for cerebral aneurysm pathology," Stroke, vol. 43, Article ID A110, 2012.

[105] F. Dandré and G. K. Owens, "Platelet-derived growth factor-BB and Ets-1 transcription factor negatively regulate transcription of multiple smooth muscle cell differentiation marker genes," American Journal of Physiology-Heart and Circulatory Physiology, vol. 286, no. 6, pp. H2042-H2051, 2004.

[106] Y. Zhang, K. K. Griendling, A. Dikalova, G. K. Owens, and W. R. Taylor, "Vascular hypertrophy in angiotensin II-induced hypertension is mediated by vascular smooth muscle cellderived $\mathrm{H}_{2} \mathrm{O}_{2}$, Hypertension, vol. 46, no. 4, pp. 732-737, 2005.

[107] G. Di Luozzo, S. Pradhan, A. K. Dhadwal, A. Chen, H. Ueno, and B. E. Sumpio, "Nicotine induces mitogen-activated protein kinase dependent vascular smooth muscle cell migration," Atherosclerosis, vol. 178, no. 2, pp. 271-277, 2005.

[108] S. Yoshiyama, T. Horinouchi, S. Miwa, H. H. Wang, K. Kohama, and A. Nakamura, "Effect of cigarette smoke components on vascular smooth muscle cell migration toward platelet-derived growth factor BB," Journal of Pharmacological Sciences, vol. 115, no. 4, pp. 532-535, 2011.

[109] J. J. Stein, K. A. Seymour, K. G. Maier, and V. Gahtan, “The effects of nicotine on vascular smooth muscle cell chemotaxis induced by thrombospondin-1 and fibronectin," The American Journal of Surgery, vol. 202, no. 5, pp. 545-548, 2011.

[110] A. Cucina, A. Fuso, P. Coluccia, and A. Cavallaro, "Nicotine Inhibits Apoptosis and Stimulates Proliferation in Aortic
Smooth Muscle Cells Through a Functional Nicotinic Acetylcholine Receptor," Journal of Surgical Research, vol. 150, no. 2, pp. 227-235, 2008.

[111] C. S. Carty, M. Huribal, B. U. Marsan, J. J. Ricotta, and M. Dryjski, "Nicotine and its metabolite cotinine are mitogenic for human vascular smooth muscle cells," Journal of Vascular Surgery, vol. 25, no. 4, pp. 682-688, 1997.

[112] J. M. Li, T. X. Cui, T. Shiuchi et al., "Nicotine Enhances Angiotensin II-Induced Mitogenic Response in Vascular Smooth Muscle Cells and Fibroblasts," Arteriosclerosis, Thrombosis, and Vascular Biology, vol. 24, no. 1, pp. 80-84, 2004.

[113] Q. W. Chen, L. Edvinsson, and C. B. Xu, "Cigarette smoke extract promotes human vascular smooth muscle cell proliferation and survival through ERK1/2- and NF- $\kappa \mathrm{B}$-dependent pathways," TheScientificWorldJournal, vol. 10, pp. 2139-2156, 2010.

[114] R. J. Anto, A. Mukhopadhyay, S. Shishodia, C. G. Gairola, and B. B. Aggarwal, "Cigarette smoke condensate activates nuclear transcription factor- $\kappa \mathrm{B}$ through phosphorylation and degradation of $\mathrm{I} \kappa \mathrm{B} \alpha$ : correlation with induction of cyclooxygenase-2," Carcinogenesis, vol. 23, no. 9, pp. 15111518, 2002.

[115] J. L. Wright, H. Tai, R. Wang, X. Wang, and A. Churg, "Cigarette smoke upregulates pulmonary vascular matrix metalloproteinases via TNF- $\alpha$ signaling," American Journal of Physiology-Lung Cellular and Molecular Physiology, vol. 292, no. 1, pp. L125-L133, 2007.

[116] M. I. Ryder, M. Saghizadeh, Y. Ding, N. Nguyen, and A. Soskolne, "Effects of tobacco smoke on the secretion of interleukin- $1 \beta$, tumor necrosis factor- $\alpha$, and transforming growth factor- $\beta$ from peripheral blood mononuclear cells," Oral Microbiology and Immunology, vol. 17, no. 6, pp. 331336, 2002.

[117] R. P. Tracy, B. M. Psaty, E. Macy et al., "Lifetime smoking exposure affects the association of C-reactive protein with cardiovascular disease risk factors and subclinical disease in healthy elderly subjects," Arteriosclerosis, Thrombosis, and Vascular Biology, vol. 17, no. 10, pp. 2167-2176, 1997.

[118] E. A. Bermudez, N. Rifai, J. E. Buring, J. E. Manson, and P. M. Ridker, "Relation between markers of systemic vascular inflammation and smoking in women," American Journal of Cardiology, vol. 89, no. 9, pp. 1117-1119, 2002.

[119] M. A. Mendall, P. Patel, M. Asante et al., "Relation of serum cytokine concentrations to cardiovascular risk factors and coronary heart disease," Heart, vol. 78, no. 3, pp. 273-277, 1997.

[120] S. H. Sun, W. X. Tang, C. Liu, H. Lin, and H. H. Yang, "Effects of tumor necrosis factor alpha on proteolysis of respiratory muscles in rats with chronic obstructive pulmonary disease," Chinese Journal of Tuberculosis and Respiratory Diseases, vol. 30, no. 3, pp. 186-191, 2007.

[121] T. Moriwaki, Y. Takagi, N. Sadamasa, T. Aoki, K. Nozaki, and N. Hashimoto, "Impaired progression of cerebral aneurysms in interleukin-1 $\beta$-deficient mice," Stroke, vol. 37, no. 3, pp. 900-905, 2006.

[122] T. Aoki, H. Kataoka, R. Ishibashi, K. Nozaki, R. Morishita, and N. Hashimoto, "Reduced collagen biosynthesis is the hallmark of cerebral aneurysm: contribution of interleukin$1 \beta$ and nuclear factor- $\kappa \mathrm{B}$," Arteriosclerosis, Thrombosis, and Vascular Biology, vol. 29, no. 7, pp. 1080-1086, 2009.

[123] T. Jayaraman, A. Paget, Y. S. Shin et al., "TNF- $\alpha$-mediated inflammation in cerebral aneurysms: a potential link to 
growth and rupture," Vascular Health and Risk Management, vol. 4, no. 4, pp. 805-817, 2008.

[124] T. Jayaraman, V. Berenstein, X. Li et al., "Tumor necrosis factor $\alpha$ is a key modulator of inflammation in cerebral aneurysms," Neurosurgery, vol. 57, no. 3, pp. 558-563, 2005.

[125] R. Polavarapu, M. C. Gongora, J. A. Winkles, and M. Yepes, "Tumor necrosis factor-like weak inducer of apoptosis increases the permeability of the neurovascular unit through nuclear factor- $\kappa \mathrm{B}$ pathway activation," Journal of Neuroscience, vol. 25, no. 44, pp. 10094-10100, 2005.

[126] P. McColgan, K. Z. Thant, and P. Sharma, "The genetics of sporadic ruptured and unruptured intracranial aneurysms: a genetic meta-analysis of 8 genes and 13 polymorphisms in approximately 20,000 individuals," Journal of Neurosurgery, vol. 112, no. 4, pp. 714-721, 2010.

[127] R. van den Berg, G. R. M. M. Haenen, H. Van Den Berg, and A. Bast, "Nuclear factor- $\kappa \mathrm{B}$ activation is higher in peripheral blood mononuclear cells of male smokers," Environmental Toxicology and Pharmacology, vol. 9, no. 4, pp. 147-151, 2001.

[128] Y. Kanematsu, M. Kanematsu, C. Kurihara et al., "Critical roles of macrophages in the formation of intracranial aneurysm," Stroke, vol. 42, no. 1, pp. 173-178, 2011.

[129] T. Aoki, H. Kataoka, R. Ishibashi, K. Nozaki, K. Egashira, and N. Hashimoto, "Impact of monocyte chemoattractant protein-1 deficiency on cerebral aneurysm formation," Stroke, vol. 40, no. 3, pp. 942-951, 2009.

[130] N. Zou, J. Hong, and Q. Y. Dai, "Passive cigarette smoking induces inflammatory injury in human arterial walls," Chinese Medical Journal, vol. 122, no. 4, pp. 444-448, 2009.

[131] R. Ishibashi, T. Aoki, M. Nishimura, N. Hashimoto, and S. Miyamoto, "Contribution of mast cells to cerebral aneurysm formation," Current Neurovascular Research, vol. 7, no. 2, pp. 113-124, 2010.

[132] S. Kangavari, S. Matetzky, P. K. Shah et al., "Smoking increases inflammation and metalloproteinase expression in human carotid atherosclerotic plaques," Journal of Cardiovascular Pharmacology and Therapeutics, vol. 9, no. 4, pp. 291298, 2004.

[133] P. Vikman, C. B. Xu, and L. Edvinsson, "Lipid-soluble cigarette smoking particles induce expression of inflammatory and extracellularmatrix-related genes in rat cerebral arteries," Vascular Health and Risk Management, vol. 5, pp. 333-341, 2009.

[134] S. C. Kim, M. Singh, J. Huang et al., "Matrix metalloproteinase-9 in cerebral aneurysms," Neurosurgery, vol. 41, no. 3, pp. 642-647, 1997.

[135] S. Horstmann, Y. Su, J. Koziol, U. Meyding-Lamadé, S. Nagel, and S. Wagner, "MMP-2 and MMP-9 levels in peripheral blood after subarachnoid hemorrhage," Journal of the Neurological Sciences, vol. 251, no. 1-2, pp. 82-86, 2006.

[136] J. H. N. Lindeman, H. Abdul-Hussien, J. H. Van Bockel, R. Wolterbeek, and R. Kleemann, "Clinical trial of doxycycline for matrix metalloproteinase-9 inhibition in patients with an abdominal aneurysm doxycycline selectively depletes aortic wall neutrophils and cytotoxic t cells," Circulation, vol. 119, no. 16, pp. 2209-2216, 2009.

[137] M. Raveendran, D. Senthil, B. Utama et al., "Cigarette suppresses the expression of $\mathrm{P} 4 \mathrm{H} \alpha$ and vascular collagen production," Biochemical and Biophysical Research Communications, vol. 323, no. 2, pp. 592-598, 2004.

[138] T. Aoki, M. Nishimura, H. Kataoka, R. Ishibashi, K. Nozaki, and N. Hashimoto, "Reactive oxygen species modulate growth of cerebral aneurysms: a study using the free radical scavenger edaravone and p47phox -/- mice," Laboratory Investigation, vol. 89, no. 7, pp. 730-741, 2009.

[139] M. A. H. Talukder, W. M. Johnson, S. Varadharaj et al., "Chronic cigarette smoking causes hypertension, increased oxidative stress, impaired NO bioavailability, endothelial dysfunction, and cardiac remodeling in mice," American Journal of Physiology-Heart and Circulatory Physiology, vol. 300, no. 1, pp. H388-H396, 2011.

[140] J. T. Powell, "Vascular damage from smoking: disease mechanisms at the arterial wall," Vascular Medicine, vol. 3, no. 1, pp. 21-28, 1998.

[141] T. Heitzer, C. Brockhoff, B. Mayer et al., "Tetrahydrobiopterin improves endothelium-dependent vasodilation in chronic smokers: evidence for a dysfunctional nitric oxide synthase," Circulation Research, vol. 86, no. 2, pp. E36-41, 2000.

[142] A. Churg, "Interactions of exogenous or evoked agents and particles: the role of reactive oxygen species," Free Radical Biology and Medicine, vol. 34, no. 10, pp. 1230-1235, 2003.

[143] R. S. Barua, J. A. Ambrose, S. Srivastava, M. C. DeVoe, and L. J. Eales-Reynolds, "Reactive oxygen species are involved in smoking-induced dysfunction of nitric oxide biosynthesis and upregulation of endothelial nitric oxide synthase: an in vitro demonstration in human coronary artery endothelial cells," Circulation, vol. 107, no. 18, pp. 2342-2347, 2003.

[144] T. Heitzer, H. Just, and T. Münzel, "Antioxidant Vitamin C Improves Endothelial Dysfunction in Chronic Smokers," Circulation, vol. 94, no. 1, pp. 6-9, 1996.

[145] F. M. Fennessy, D. S. Moneley, J. H. Wang, C. J. Kelly, and D. J. Bouchier-Hayes, "Taurine and vitamin C modify monocyte and endothelial dysfunction in young smokers," Circulation, vol. 107, no. 3, pp. 410-415, 2003.

[146] G. J. Miller, K. A. Bauer, J. A. Cooper, and R. D. Rosenberg, "Activation of the coagulant pathway in cigarette smokers," Thrombosis and Haemostasis, vol. 79, no. 3, pp. 549-553, 1998.

[147] R. Zidovetzki, P. Chen, M. Fisher, and F. M. Hofman, "Nicotine increases plasminogen activator inhibitor-1 production by human brain endothelial cells via protein kinase Cassociated pathway," Stroke, vol. 30, no. 3, pp. 651-655, 1999.

[148] P. A. Wolf, R. B. D’Agostino, W. B. Kannel, R. Bonita, and A. J. Belanger, "Cigarette smoking as a risk factor for stroke. The Framingham study," Journal of the American Medical Association, vol. 259, no. 7, pp. 1025-1029, 1988.

[149] R. S. Barua, J. A. Ambrose, D. C. Saha, and L. J. EalesReynolds, "Smoking is associated with altered endothelialderived fibrinolytic and antithrombotic factors: an in vitro demonstration," Circulation, vol. 106, no. 8, pp. 905-908, 2002.

[150] A. Sambola, J. Osende, J. Hathcock et al., "Role of risk factors in the modulation of tissue factor activity and blood thrombogenicity," Circulation, vol. 107, no. 7, pp. 973-977, 2003.

[151] J. W. Peterson, B. D. Kwun, A. Teramura et al., "Immunological reaction against the aging human subarachnoid erythrocyte. A model for the onset of cerebral vasospasm after subarachnoid hemorrhage," Journal of Neurosurgery, vol. 71, no. 5, pp. 718-726, 1989. 


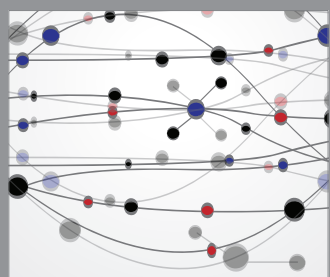

The Scientific World Journal
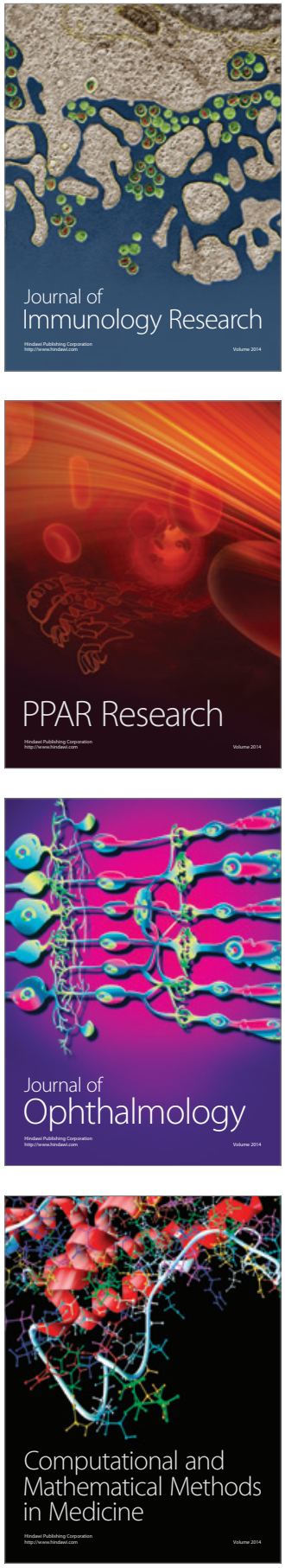

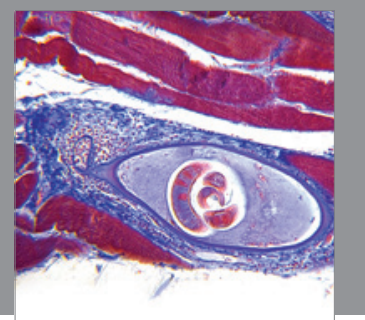

Gastroenterology

Research and Practice
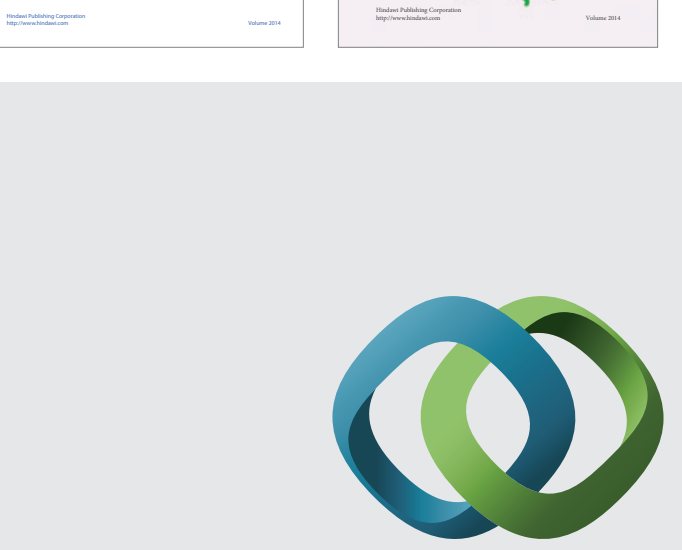

\section{Hindawi}

Submit your manuscripts at

http://www.hindawi.com
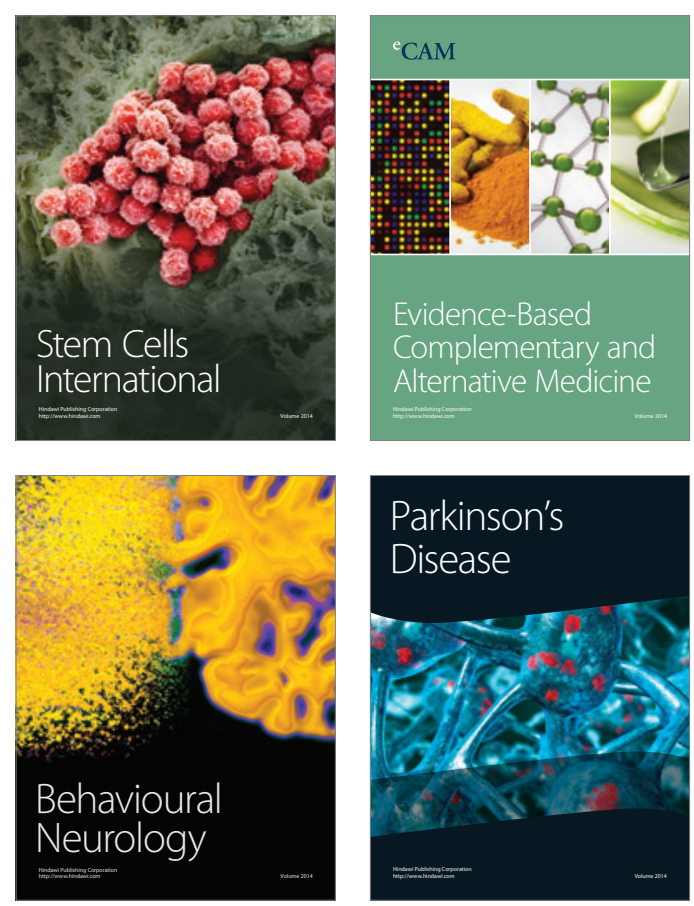

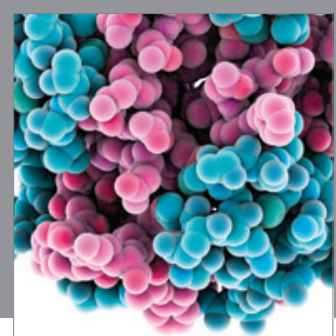

Journal of
Diabetes Research

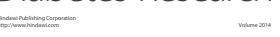

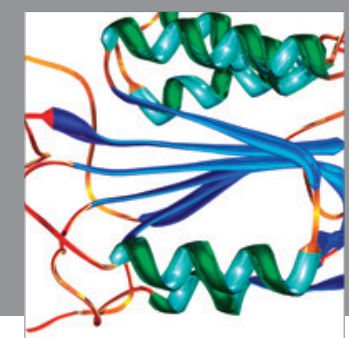

Disease Markers
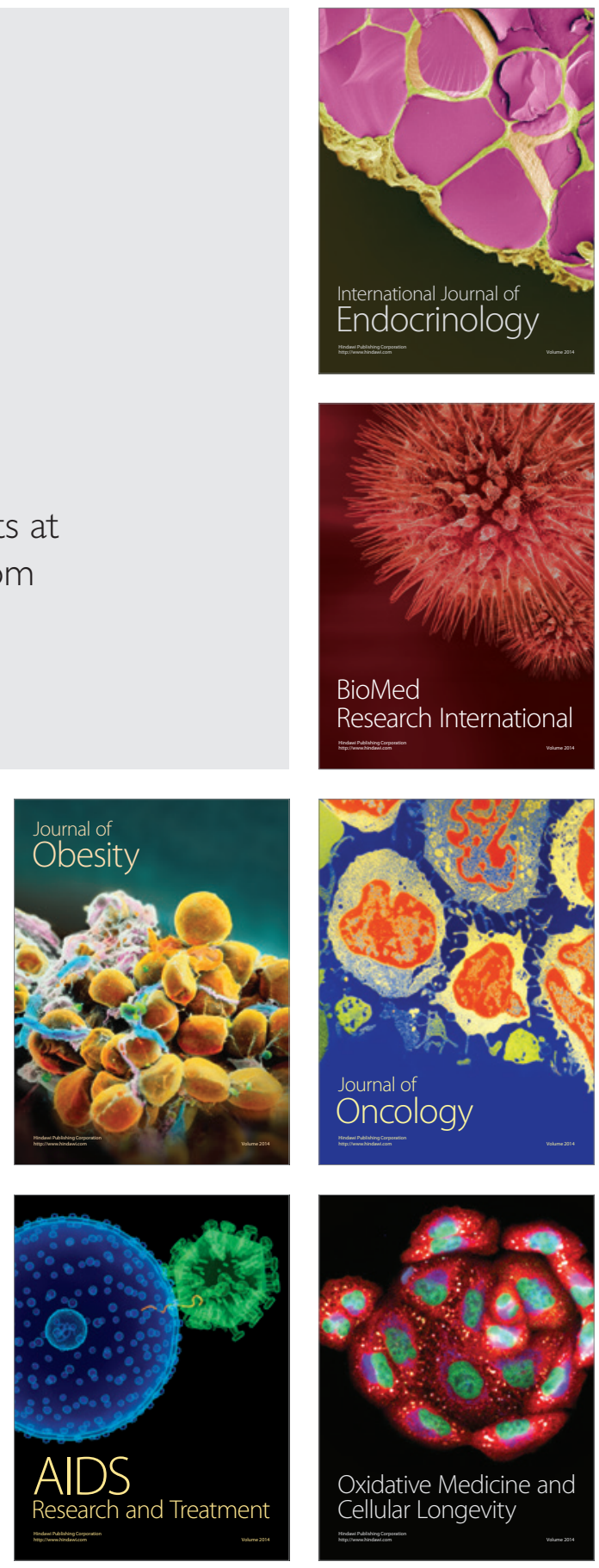